DOI: https://doi.org/10.24297/jal.v12i.9140

\title{
A Corpus-based Contrastive Study on English and Chinese Semantic Prime happen and fasheng in Natural Semantic Metalanguage
}

\author{
Yajun Wang \\ School of Interpreting and Translation Studies, \\ Guangdong University of Foreign Studies, Guangzhou, China
}

\begin{abstract}
This paper reports a corpus-based study on English and Chinese semantic prime happen and fasheng in Natural Semantic Metalanguage. With the aids of computer software Wordsmith 5.0 and SPSS19.0, we conducted a contrastive study on happen and fasheng based on a small English and Chinese comparable corpus constructed by ourselves. By extracting evidence from the corpus, the distribution of happen and fasheng, their syntactic patterns, their colligation types as well as their semantic prosody are identified and analyzed. We found that there is no significant difference between English semantic prime happen and its Chinese counterpart fasheng with respect to their distribution, their syntactic patterns, their colligations, and their semantic prosody. The results reveal that semantic prime happen is identical with its Chinese counterpart fasheng. Thus it provides an evidence to justify the premise of the Natural Semantic Metalanguage Theory.
\end{abstract}

Key words: Corpus, NSM, Semantic primes, Semantic prosody, happen, fasheng

\section{Introduction}

As language is an important tool for human communication as well as a carrier of culture, its appropriate use in cross-cultural communication has always been considered important. Natural Semantic Metalanguage (NSM) is a good approach when it comes to lexical semantic analysis. The theory began as a method of lexical semantic analysis based on reductive paraphrase; that is, on the idea that the meaning of any semantically complex word can be explicated by means of an exact paraphrase composed of simpler, more intelligible words than the original (Wierzbicka, 1972), thus it voids the circularity and terminological obscurity in most dictionaries. It follows that every language has an irreducible "semantic core" which would be used in dealing with all the complex expressions. This semantic core must have a language-like structure, with a lexicon of indefinable expressions (semantic primes) and a grammar, which is the principle governing how the lexical elements can be combined. The semantic primes and their principles of combination constitute a kind of "mini-language" with the same expressive power as a full natural language.

By an extensive program of trial and error attempts to explicate meanings of diverse types, Anna Wierzbicka with other scholars have done over a period of thirty years to find the set of 60 or so semantic primes, i.e. indefinable meanings. Some of the primes are: I, YOU, SOMEONE, SOMETHING, THIS, HAPPEN, MOVE, KNOW, THINK, WANT, SAY, WHERE, WHEN (see Table 1). The claim is that the meanings of these words are essential for explicating the meanings of numerous other words and grammatical constructions, and that they cannot themselves be explicated in a non-circular fashion (Goddard, C., Wierzbicka, A., 1994, 2002, 2014). These elements are held to designate meanings which are impervious to (non-circular) definition and are universal in the sense of having equivalents in all languages. By relying on a specified, minimal metalanguage, the approach aims to maximize explicitness, clarity, and translatability. The NSM explications can, however, readily accommodate vagueness and reflect elements of subjectivity (Goddard, 1998a). A considerable number of cross-linguistic researches indicate that the same set of semantic primes can be found, expressed via words or word-like elements, in a diverse range of languages. 
Table 1: Proposed universal semantic primes (Goddard and Wierzbicka, 2014).

\begin{tabular}{|c|c|}
\hline Substantives: & $\begin{array}{l}\text { SOMETHING THING shénme yǒu shì, BODY shēntǐ, I ME wǒ, YOU nǐ, SOMEONE } \\
\text { shéi yǒu rén, PEOPLE rénmen rén }\end{array}$ \\
\hline Relational substantives: & KIND zhǒng lèi, PART bù fèn \\
\hline Determiners: & THIS zhè(ge), THE SAME tóngyàng tóngȳ̄ yīyàng, \\
\hline Quantifiers: & $\begin{array}{l}\text { ONE yī(ge), TWo liǎng, SOME yǒu de yīxīe, ALL dōu, MANY/MUCH (hên) duō, } \\
\text { LITTLE FEW (hěn) shǎo }\end{array}$ \\
\hline Evaluators: & GOOD hǎo, BAD huài bùhǎo \\
\hline Descriptors: & BIG dà, SMALL xiăo \\
\hline Mental predicates: & $\begin{array}{l}\text { THINK xiăng, KNOW zhīdao, WANT yào, DON'T WANT bú (xiǎng) yào, FEEL gănjué, } \\
\text { SEE kàndào, HEAR tīngdào }\end{array}$ \\
\hline Speech: & SAY shuō, WORDS zì huà, TRUE zhēn \\
\hline $\begin{array}{l}\text { Actions, events, } \\
\text { movement, contact: }\end{array}$ & DO zuò, HAPPEN fāshēng, MOVE dòng, TOUCH chù mō \\
\hline $\begin{array}{l}\text { Location, existence, } \\
\text { specification, } \\
\text { possession: }\end{array}$ & $\begin{array}{l}\text { BE (SOMEWHERE) zài(năr), THERE IS yǒu, BE (SOMEONE/SOMETHING) shì } \\
\text { (shéi/shénme), BE(SOMEONE'S) shì( shuí de) }\end{array}$ \\
\hline Life and death: & LIVE shēnghuó huó, DIE sǐ \\
\hline Time: & $\begin{array}{l}\text { WHEN TIME shíhou shí jiān, NOW xiànzài, BEFORE y̌̌qián, AFTER yǐhòu, A LONG TIME } \\
\text { hěnjiǔ, A SHORT TIME duănqi, FOR SOME TIME yǒuyīduàn shíiiān, MOMENT shùn jiān } \\
\text { yī huì er }\end{array}$ \\
\hline Space: & $\begin{array}{l}\text { WHERE PLACE shénme/difāng nǎr/nàr, HERE zhèr, ABOVE shàngmian -shang, BELOW } \\
\text { xiàmian -xia, FAR yuăn, NEAR jìn (de)shēnbian, SIDE -bian, INSIDE lǐmian }\end{array}$ \\
\hline Logical concepts: & NOT bù, MAYBE kěnéng, CAN néng, BECAUSE yīnwèi, IF rúguǒ \\
\hline Augmentor, intensifier : & VERY hěn, MORE duō \\
\hline Similarity: & LIK \\
\hline
\end{tabular}

\footnotetext{
"The semantic metalanguage has not been fully described until its syntax (i.e. combinatorial properties) has been fully specified. Nor, until this has been done, can we know whether the goal of a universal semantic metalanguage is realizable at all." (Goddard, 2002: 32) The existence of some shared or matching combinatorial patterns across all languages is just as important to the project as the existence of shared semantic primes. A corpus-based study takes advantage of the very best sources-examples from a large body of naturally occurring texts which pool together the intuitions of a great number of speakers and make linguistic analysis more objective. Until now, no research has been conducted based on corpus in this respect. So the current study tries to achieve a marriage between theory-driven and corpus-based approaches to linguistics through a contrastive study on English and Chinese semantic prime happen and fasheng. The use of corpus data as an
} 
input to the analysis of semantic primes represents something new. The marriage of the corpus-based approach and traditional NSM analysis has enabled this thesis to produce a more realistic account in a way that has not been attempted previously.

\section{Methodology}

\subsection{Construction of the Corpus}

In planning the collection of texts to be included in our corpora, two considerations were made beforehand. One is that a variety of different genres of writing would be gathered for inclusion in the corpus. The other is that each genre would be divided into text samples, and each sample would not exceed a certain amount of words in length.

After comparing the resources and the amount of time available to create our own comparable corpus, we determined that the English corpus should contain 500000 words. According to Hu (2006), 10 English words equal to 16 Chinese characters, so the Chinese corpus should contain 800000 characters. The list of main categories and their subdivisions was drawn up according to the layout of Brown Corpus. A few changes were later made on the basis of experience gained in making the selections.

\subsection{Data collection}

In our comparable corpus, the texts in each corpus are divided into two main categories: informative prose and imaginative prose. The category of informative prose includes academic writing, non-academic writing and press reportage. Academic writing is represented by journal articles and textbooks, and covers a wide variety of topics, including natural sciences, medicine, mathematics, social and behavioral sciences, political science, law, education, humanities, technology and engineering. In contrast with that, non-academic writing has a wider and more varied readership, although the subject areas may still be quite specialized. This category includes press reportage, press editorials, press reviews, skills and hobbies, popular lore, miscellaneous and bells letters, biography, memoirs, etc. Press reportage includes political, sports, society, financial and cultural reports. All the reports were written by staff reporters and journalists. Each corpus contains a total of 22 individual press reports, taken from national, regional, and local newspapers. Press editorials and press reviews are distinguished from general news reports in the grounds that their main intention is to persuade rather than to inform. They are less directly tied to current events, and they offer the writer the opportunity to be discursive in a way that news journalism does not. Miscellaneous is corporate in origin. It is written on behalf of government departments or other administrative bodies and its chief aim is to convey information to the general public. Texts in the skill and hobbies category also offer instruction, but these are directed towards a smaller and more specialized readership. They include car maintenance manuals, cookery books, gardening manuals etc.

The imaginative prose in the corpus is creative writing: novels and short stories. It includes a variety of fiction types, including general fiction, mystery and detective fiction, science fiction, adventure fiction, romance and love story and humor.

Once the basic outlines of the corpus are determined, it is time to begin the actual creation of the corpus: collection, computerization, sampling, and segmentation of the Chinese characters.

The samples represent a wide range of styles and varieties of prose. Samples were chosen for their representative quality rather than for any subjectively determined excellence. Most of the samples were written in recent years. Since new words come into the language every day, we decided that for magazines and newspapers, the time-frame was one year, and for books, the time frame was five to ten years. 
After the collection of the data, each text was assigned a unique textcode, corresponding to its position in the hierarchy of text categories in the corpus in which the sample might be included. As for the sampling, the number of texts in each category varies. For the English corpus, each sample is of $2000+$ words. According to $\mathrm{Hu}$ (2006), its Chinese counterpart is of $3200+$ characters. Each sample begins at the beginning of a sentence but not necessarily of a paragraph or other larger division, and each ends at the first sentence ending after 2000 words or 3200 characters.

The detailed information about the corpus is shown in table 2 .

Table 2: Detailed information about the corpus

\begin{tabular}{|l|l|l|}
\hline & English & Chinese \\
\hline Running words in texts (Tokens) & 505848 & 461912 \\
\hline Distinct words (Types) & 30955 & 30683 \\
\hline Type/Token ratio (TTR) & 6.12 & 6.64 \\
\hline Standardized TTR & 45.16 & 48.67 \\
\hline Standardized TTR std. dev. & 53.56 & 50.60 \\
\hline
\end{tabular}

\section{Data Analysis and Discussion}

"The ability to examine large text corpora in a systematic manner allows access to a quality of evidence that has not been available before." (Sinclair, 1991:27) The present study is a corpus-based study and tries to make a combination of quantitative measurements and qualitative analysis of the English and Chinese semantic prime happen and fasheng. By extracting evidence from corpora, the distribution of happen and fasheng, their syntactic patterns, colligation types, collocations as well as their semantic prosody are presented and analyzed.

\subsection{Dictionary Explanation of happen and fasheng}

In the Collins CoBuild Advanced Learner's English Dictionary (2006), happen is defined as follows:

1. Something that happens occurs or is done without being planned.

2. If something happens, it occurs as a result of a situation or course of action.

3. When something, especially something unpleasant, happens to you, it takes place and affects you.

4. If you happen to do something, you do it by chance. If it happens that something is the case, it occurs by chance.

5. You use as it happens in order to introduce a statement, especially one that is rather surprising.

1. In the Oxford Advanced Learner's English-Chinese Dictionary (2004), the explanation is as follows:

1. to take place, especially without being planned. (尤指偶然) 发生, 出现.

2. to take place as the result of sth. (作为结果) 出现, 发生

3. to do or be sth. by chance. 碰巧做, 恰好是

4. used to tell sb. sth., especially when you are disagreeing with them or annoyed by what they have said. 向对方表示异议或不悦等 
In 《现代汉语辞海》(Xian Dai Han Yu Ci Hai) (Dictionary of Contemporary Chinese) (1994), the word fasheng is defined as "yuanlai meiyou de shiwu chuxian-le; chansheng" “原来没有的事物出现了; 产生" (new things appear; take place). While in 《现代汉语词典》(Xian Dai Han Yu Ci Dian) (Modern Chinese Dictionary) (2005), the word fasheng is explained as follows:

1. yuanlai meiyou de shi chuxian-le; chansheng 原来没有的事出现了; 产生

New things appear; take place

2. luanzi shoujing hou zhujian shengzhang 卵子受精后逐渐生长

Gradual development of an embryo

According to the NSM Theory, only the "take place" sense of the word happen is proposed as the semantic prime. In like manner, only the "yuanlai meiyou de shi chuxian-le; chansheng" (new things appear; take place) sense of fasheng is proposed as the semantic prime.

\subsection{Distribution of happen and fasheng}

In this section, the overall frequencies of happen and fasheng as well as the respective frequencies of happen and fasheng with different meanings are presented and analyzed.

\subsubsection{Overall distribution of happen and fasheng}

To investigate the usage of happen and fasheng in the comparable corpus, the raw frequencies were calculated and the results are listed in Table 3.

Table 3: Overall frequency of happen and fasheng

\begin{tabular}{|l|l|l|l|}
\hline & Raw frequency & Number of words & Percentage \\
\hline happen & 120 & 505848 & $0.02372 \%$ \\
\hline fasheng & 194 & 461912 & $0.04199 \%$ \\
\hline
\end{tabular}

As shown in Table 3, the total frequency of happen is 120, while that of fasheng is 194. The proportion of happen in English corpus is $0.02372 \%$ which is lower than that of fasheng $0.04199 \%$. To test whether the difference is due to the different sizes of the corpora used for comparison, we resort to a statistical tool. "The aim of statistical tests of significance is to show whether or not the observed differences between sets of data could reasonably have been expected to occur 'by chance' or whether; on the contrary, they are most probably due to the alternation in the variable whose effect is being investigated." (Bulter, 1985: 8) Chi-square tests were performed with SPSS 10.0 in order to find out whether the difference in frequencies is significant at five percent significance level. The result is shown in Table 4.

Table 4: Chi-square tests on total frequency of happen and fasheng

\begin{tabular}{|l|l|l|l|}
\hline & $\chi^{2}$ & $d f$ & $p$ \\
\hline Overall frequency & 24.87 & 1 & .000 \\
\hline
\end{tabular}

As shown in Table 4, degree of freedom is 1 . The calculated Chi-square value is 24.87, much greater than the critical value 3.38 at five percent level. The calculated significance is .000 much smaller than .05 . Thus we may 
conclude that the overall distribution of happen and fasheng in the comparable corpus is significantly different. The reason for this is that the vocabulary entry of happen and fasheng are not entirely equal. Both happen and fasheng are polysemous words. Of the several meanings of happen, only the first sense "to take place" is proposed as a semantic prime. In like manner, only the first sense of fasheng: "yuanlai meiyou de shi chuxian-le; chansheng" (new things appear; take place) is proposed as a semantic prime. The following are several examples of the sense of happen and fasheng proposed as the semantic primes.

[1]

a. What happened to those cells when people lost weight, he wondered.

b. But what happens if Canada and Brazil wine and crop prices later drop sharply?

c. The day came when it did happen and when they wished themselves elsewhere.

d. Then everything happened, and with inconceivable rapidity.

e. 一定会发生感染。

yidinghui fasheng ganran

certainly happen infection

The infection would certainly take place.

f. 发生翻车事故。

fasheng fanche shigu

happen overturned car accident

The overturned vehicle accident happened.

g. 发生通货膨胀。

fasheng tonghuopengzhang

happen inflation

The inflation happened.

h. 谁也不敢问，会有什么事发生。

shui ye bugan wen, hui you shenmeshi fasheng

Who also daren't ask should have what happen

Nobody dares to ask what will happen.

Example [1a] can be interpreted as "He wondered what would take place to those cells when people lost weight." Example [1b] means that "What would occur as a result of the sharply reduction of the price of wine and crop in Canada and Brazil." In the above examples happen means "take place, occur". In example [1e], it means that new thing infection would appear. In example [1g], there is no doubt that the inflation is the consequence of something.

Several examples of the uses that cannot be proposed as the semantic primes are illustrated as follows:

[2] 
a. Has something happened to alter him, or is that his natural state?

b. How did you happen to be shod with gold?

c. One morning I happened to turn over the salt-cellar at breakfast.

d. As it happens, I have my notebook with me.

Here, happen means "to do or be something by chance". In Chinese, it means pengqiao, qiaqiao. Example [2d] can be interpreted as "It is by chance that I have my notebook with me." In Chinese, it is "qiaqiao wo dai le bi". "Happen to do something" means "to do something by chance". Such as example [2c], it means that "One morning I turned over the salt-cellar at breakfast by chance."

[3]

a. The two friends happened on each other in a town.

b. I happened on the pen I'd been looking for.

In the above two examples, happen also means "occur by chance". The Chinese equivalences are ouran yudao, ouran faxian. Example [3a] can be interpreted as "The two friends met each other in a town by chance." In Chinese, it is "liang wei pengyou zai yige chengzhen ouran yudao le". While example [3b] means "By chance I found the pen l'd been looking for."

[4]

a. 预防腐败现象的发生。

yufang fubai xianxiang de fasheng

prevent corruption phenomena happen

To prevent the happening of the corruption.

b. 避免火灾的发生。

bimian huozai de fasheng

avoid fire happen

To avoid the happening of the fire.

In the above two examples, fasheng means "something that happens". Here fasheng is a noun, and its English counterpart is happening. "huozai de fasheng"means "the happening of the fire", which is different from "huozai fasheng" and "fasheng huozai", which means "the fire happened".

[5]

\section{a. 他们对发生的事件总感到突兀。}

tamen dui fasheng de shijian zong gandao tuwu

they towards happen thing always feel abrupt

They always feel abrupt to the things that happened.

b. 这是小时候所发生的事情。

zhe shi xiaoshihou suo fasheng de shiqing 
This is childhood happen thing

This is the thing that happened during childhood.

Here fasheng is an attribute, modifying shi (thing), which means "that happened". "fasheng de shiqing" means "the thing that happened", which is different from "shiqing fasheng" (the thing happened).

Since the present study is to analyze the semantic prime happen and fasheng, we only focus on the sense proposed as the semantic prime.

\subsubsection{Frequencies of happen and fasheng with different meanings}

To investigate the usages of semantic prime happen and fasheng in the comparable corpus, the distribution of happen and fasheng with different meanings were calculated and the results are shown in Table 5.

Table 5: Frequencies of happen and fasheng with different meanings

\begin{tabular}{|l|l|l|l|l|}
\hline & \multicolumn{2}{|l|}{ happen } & fasheng \\
\hline & Frequency & Percentage & Frequency & Percentage \\
\hline Semantic prime meaning & 98 & $81.67 \%$ & 146 & $75.26 \%$ \\
\hline Other meanings & 22 & $18.33 \%$ & 48 & $24.74 \%$ \\
\hline Total & 120 & $100 \%$ & 194 & $100 \%$ \\
\hline
\end{tabular}

As shown in Table 5, there is still a discrepancy in the different meanings of happen and fasheng: semantic prime meaning of happen accounts for $81.67 \%$ while that of fasheng is $75.26 \%$. Based on the raw data in Table 5 , Chi-square tests were performed to find out whether the distribution of happen with semantic prime meaning differs significantly to that of fasheng at five percent significant level. Table 6 shows the result of Chi-square test of the comparison of semantic prime meaning of happen and fasheng after running SPSS programs.

Table 6: Chi-square tests on semantic prime meaning of happen and fasheng

\begin{tabular}{|l|l|l|l|}
\hline & $\chi^{2}$ & $d f$ & $p$ \\
\hline Selected frequency & 1.76 & 1 & .185 \\
\hline
\end{tabular}

For Table 6, degree of freedom is 1 . The calculated value is 1.76 , which is smaller than the critical value 3.38 at five percent level. The calculated significance is .185 much greater than .05 . Thus we can tell that there is no significant difference of the distribution of semantic prime happen and fasheng.

\subsection{Syntactic Patterns of happen and fasheng}

Based on the concordance lines of happen and fasheng, we have identified three syntactic patterns for happen and fasheng.

\section{SOMETHING HAPPEN \\ EVENT-NOUN fasheng \\ fasheng EVENT-NOUN}




\section{SOMETHING HAPPEN TO X [Undergoer] \\ EVENT-NOUN fasheng zai X [Undergoer] (de) shenshang \\ $\mathrm{X}$ [Undergoer] fasheng EVENT-NOUN \\ III. SOMETHING HAPPEN IN PLACE/TIME \\ EVENT-NOUN fasheng zai NP TIME/PLACE \\ NPTIME/PLACE fasheng EVENT-NOUN}

Let us first examine the syntactic frame for happen and fasheng with event nouns. Pattern I in Chinese contains a single "eventive" argument which may occur preverbally or postverbally. Generally speaking, the difference in position depends on information status. New information is postverbal, while given information tends to be preverbal. While in English, happen is an intransitive verb, so the "eventive" argument only occurs preverbally. Several examples are given below:

[6]
a. Letting everyone know exactly what did happen.
b. I can't believe this is happening!
c.必将会发生一场浩劫。
bijiang hui fasheng yichang haojie
certainly should happen a catastrophe
There will certainly be a catastrophe.
d. 意外发生了。

$$
\text { yiwai fasheng-le }
$$$$
\text { accident happened }
$$

The accident happened.

For pattern II, " $\mathrm{X}$ " is the undergoer, i.e. the role borne by " $\mathrm{X}$ ". In Chinese, the noun in preverbal position is interpreted as the undergoer, while the second slot is always the event noun. In order to code the undergoer as opposed to locus, a different structure is used with a postverbal locative phrase zai X (de) shenshang which collocates the undergoer with shenshang. Here the bound lexeme shen refers to what happens to one's body as a literal embodiment of "person, self, life" (Goddard, 2002). This is the only frame with happen and fasheng that allows both undergoer and event to be introduced. Several examples are given below:

[7]

a. But what happens to you, my orphan?

b. Obi Wan never told you what happened to your father.

C. 身体就会发生故障。

shenti jiuhui fasheng guzhang

body will happen trouble

There will be something wrong with the body. 


\section{d. 当死亡发生在自己亲人身上。 \\ dang siwang fasheng zai ziji qinren shengshang \\ when death happen to self relatives body}

When death happens to our relatives...

For pattern III, in English, the preposition indicates a locus/time position which equals to the lexeme zai in Chinese. The locus/time noun phrase is also allowable in preverbal position. Examples are given below:

[8]

a. There is something happening in America.

b. It tells you about what had happened in the past.

c. 以前曾发生过事故。

yiqian ceng fashengguo shigu

before once happened accident

The accident happened before.

d. 事故发生在韶山路。

shigu fasheng zai shaoshan lu

accident happen in shaoshan road

The accident happened in Shaoshan road.

To investigate the usage in terms of different syntactic patterns, the frequencies of each syntactic pattern was calculated and analyzed. The results are listed below.

Table 7: Frequencies of happen and fasheng within different syntactic patterns

\begin{tabular}{|l|l|l|l|l|}
\hline \multirow{2}{*}{ Syntactic pattern } & \multicolumn{2}{|l|}{ happen } & \multicolumn{2}{l|}{ fasheng } \\
\cline { 2 - 5 } & Frequency & Percentage & Frequency & Percentage \\
\hline Pattern I & 59 & $60.20 \%$ & 71 & $48.63 \%$ \\
\hline Pattern II & 16 & $16.33 \%$ & 36 & $24.66 \%$ \\
\hline Pattern III & 23 & $23.47 \%$ & 39 & $26.71 \%$ \\
\hline Total & 98 & $100 \%$ & 146 & $100 \%$ \\
\hline
\end{tabular}

As shown in Table 7, there is a discrepancy in different syntactic patterns of happen and fasheng: syntactic pattern I of happen accounts for $60.20 \%$, while that of fasheng is $48.63 \%$; syntactic pattern II of happen accounts for $16.33 \%$, while that of fasheng is $24.66 \%$; the third syntactic pattern of happen accounts for $23.47 \%$, while that of fasheng is $26.71 \%$. Based on the raw data in Table 7, Chi-square tests were performed to find out whether the distributions of different syntactic patterns differ significantly. Table 8 shows the results of Chi-square tests of the comparison of different syntactic patterns of happen and fasheng after running SPSS program. 
Table 8: Chi-square tests on syntactic patterns of happen and fasheng

\begin{tabular}{|l|l|l|l|}
\hline & $\chi^{2}$ & $d f$ & $p$ \\
\hline Syntactic pattern I & 3.16 & 1 & .076 \\
\hline Syntactic pattern II & 2.43 & 1 & .119 \\
\hline Syntactic pattern III & 0.33 & 1 & .568 \\
\hline
\end{tabular}

For Table 8, degree of freedom is 1, the calculated Chi-square value is 3.16, 2.43, and 0.33 respectively, all smaller than the critical value 3.84 at five percent level. The calculated significance value is $.076, .119$, and .568 respectively, all bigger than the critical value .05 . Thus we may conclude that there is no significant difference between the distributions of the three syntactic patterns of happen and fasheng.

\subsection{Colligations of happen and fasheng}

In order to have a deeper understanding of the different syntactic patterns, we resort to observe the detailed colligations for each pattern. And the results are listed as below. The detailed colligations for syntactic pattern I are shown as follows:

Table 9: Colligation types within syntactic pattern I

\begin{tabular}{|l|l|l|l|l|}
\hline \multirow{2}{*}{$\begin{array}{l}\text { Colligation } \\
\text { type }\end{array}$} & \multicolumn{2}{|l|}{ happen } & fasheng \\
\cline { 2 - 5 } & Frequency & Percentage & Frequency & Percentage \\
\hline $\begin{array}{l}\text { n./ pron. + V. } \\
\text { V. + n. }\end{array}$ & 42 & $71.19 \%$ & 60 & $84.50 \%$ \\
\hline $\begin{array}{l}\text { n./ pron. + V. + adv. } \\
\text { n./ pron. + adv. + V. }\end{array}$ & 17 & $28.81 \%$ & 11 & $15.50 \%$ \\
\hline Total & 59 & $100 \%$ & 71 & $100 \%$ \\
\hline
\end{tabular}

From table 9, we can see that there are two colligation types within syntactic pattern I. happen can only be used as intransitive verb, while fasheng can be used as either transitive or intransitive verb. In syntactic pattern I, we further divide the colligation type according to whether there occurs an adverb or not. Colligation type "n./ pron. + V. or V. + $\mathrm{n}^{\prime \prime}$ within syntactic pattern I of happen accounts for $71.19 \%$, while that of fasheng is $84.50 \%$; Colligation type "n./ pron. + V. + adv. or n./ pron. + adv. + V." within syntactic pattern I of happen accounts for $28.81 \%$, while that of fasheng is $15.50 \%$. Typical examples are listed as follows:

[9]
a. That did not happen.
b. Or it could happen again.
c. 惨案发生了, 我们得到报案。
can'an fasheng le, women dedao baoan
accident happened, we got report 
The accident happened, and we got the report.

d. 你能不能告诉我, 发生了什么事情?

ni nengbuneng gaosu wo, fasheng le shenme shiqing?

you could tell me happened what thing

Will you please tell me what happened?

e. 但最糟的并不总是发生。

dan zuizaode bingbu zongshi fasheng

but the worst not always happen

The worst things do not always happen.

Example [9a], [9c], and [9d] belong to colligation type "n./ pron. + V. or V. + n." In example [9c], "can'an fasheng le" (the accident happened), the event noun can'an (the accident) occurs preverbally. In example [9d], "fasheng le shenme shiqing" (what happened), the event noun shenme shiqing (what) occurs postverbally. In English, the event noun can only occur preverbally as in example [9a]. Example [9b] and [9e] belong to colligation type "n./ pron. + V. + adv. or n./ pron. + adv. + V." The word again, zongshi (always) are adverbs modifying happen and fasheng.

The detailed colligations for syntactic pattern II are shown as follows:

Table 10: Colligation types within syntactic pattern II

\begin{tabular}{|l|l|l|l|l|}
\hline \multirow{2}{*}{$\begin{array}{l}\text { Colligation } \\
\text { type }\end{array}$} & \multicolumn{2}{|l|}{ happen } & fasheng \\
\cline { 2 - 5 } & Frequency & Percentage & Frequency & Percentage \\
\hline n. + V. + n. & 00 & 0 & 34 & $94.44 \%$ \\
\hline $\begin{array}{l}\text { n./ pron. + prep. + V. } \\
\text { n./ pron. + V. + prep. }\end{array}$ & 16 & $100 \%$ & 2 & $5.56 \%$ \\
\hline Total & 16 & $100 \%$ & 36 & $100 \%$ \\
\hline
\end{tabular}

As to the second syntactic pattern: SOMETHING HAPPEN TO X [Undergoer]. The colligation type for happen in this syntactic pattern is exclusively "n. / pron. + V. + prep." Its Chinese counterpart is "EVENT-NOUN fasheng zai X [Undergoer] (de) shenshang / X [Undergoer] fasheng EVENT-NOUN". The undergoers in Chinese usually are subjects of the sentence, so colligation type "n. + V. + n." within syntactic pattern II of fasheng is the mainstream, which accounts for $94.44 \%$ of the total, while colligation type "n. / pron. + prep. + V. or n. / pron. + V. + prep." only accounts for $5.56 \%$. Typical examples are given below:

[10]
a. I have to understand what happened to me.
b. But what happens to you, my orphan?
c. 当死亡发生在自己亲人身上。

dang siwang fasheng zai ziji qinren shengshang 
when death happen to self relatives body

When death happens to our relatives,

d. 情况发生变化。

qingkuang fasheng bianhua

situation happen change

The situation has changed.

e. 身体就会发生故障

shenti jiuhui fasheng guzhang

body will happen trouble

There will be something wrong with the body.

In example [10a] and [10b], the preposition to is to introduce the undergoer me and you. Example [10c] belongs to colligation type "n. / pron. + V. + prep.", the phrase zai X shenshang introduces the undergoer ziji qinren (our relatives), and the preverbal noun siwang is the event noun. Example [10d] and [10e] belong to colligation type "n. + V. + n.", the preverbal nouns qingkuang (situation) and shenti (body) are the undergoers, while the postverbal nouns bianhua (change) and guzhang (trouble) are the event nouns.

The detailed colligations for syntactic pattern III are shown as follows:

Table 11: Colligation types within syntactic pattern III

\begin{tabular}{|l|l|l|l|l|}
\hline \multirow{2}{*}{ Colligation type } & \multicolumn{2}{|l|}{ happen } & \multicolumn{2}{l|}{ fasheng } \\
\cline { 2 - 5 } & Frequency & Percentage & Frequency & Percentage \\
\hline V. + locus & 10 & $43.48 \%$ & 29 & $74.36 \%$ \\
\hline V. + Time & 13 & $56.52 \%$ & 10 & $25.64 \%$ \\
\hline Total & 23 & $100 \%$ & 39 & $100 \%$ \\
\hline
\end{tabular}

In syntactic pattern III, the colligation type can be further divided into "V. + locus" and "V. + Time". Within this syntactic pattern, colligation type "V. + locus" of happen accounts for $43.48 \%$, while that of fasheng is $74.36 \%$; colligation type "V. + Time" of happen accounts for $56.52 \%$, while that of fasheng is $25.64 \%$. Typical examples are given below:

[11]

a. There was also a Nascar promotion happening around Midtown.

b. It tells you about what had happened in the past.

c. 事故发生在韶山路。

shigu fasheng zai shaoshan lu

accident happen in shaoshan road

The accident happened in shaoshan road. 


\section{d. 事故多发生于三、四月份。}

shigu duo fasheng yu san, si yuefen

accident much happen at three four month

The accident usually happened in March and April.

Example [11a] and [11c] belong to colligation type "V. + locus", the preposition around and zai introduce the locus Midtown and shaoshan road. Example [11b] and [11d] belong to colligation type "V. + Time", the preposition phrase in the past and yu san, si yuefen (in March and April) indicate the time frame.

\subsection{Semantic Prosody and Collocation of happen and fasheng}

Since semantic prosody studies the collocational behavior of lexical items, and it lays its emphasis on the semantic meaning which imposes on collocational structure, we analyze the collocation and semantic prosody of happen and fasheng together.

\subsubsection{Overall semantic prosody of happen and fasheng}

In the current study, we evaluated each case in context. A pleasant or favorable affective meaning is labeled as positive while an unpleasant or unfavorable affective meaning is judged as negative. When what was happening was completely neutral, or the context provides no evidence of any semantic prosody, the instance is labeled as neutral. It has to be admitted that, since there is no agreed criterion to the classification of these three categories, discrepancies do exist for some vague words. However, we will not take this factor into consideration because they only account for a small rate in the words being examined.

Table 12: Overall semantic prosody of happen and fasheng

\begin{tabular}{|l|l|l|l|l|}
\hline \multirow{2}{*}{ Semantic prosody } & \multicolumn{2}{|l|}{ happen } & \multicolumn{2}{l|}{ fasheng } \\
\cline { 2 - 5 } & Frequency & Percentage & Frequency & Percentage \\
\hline Positive & 16 & $16.33 \%$ & 21 & $14.38 \%$ \\
\hline Negative & 50 & $41.02 \%$ & 87 & $59.59 \%$ \\
\hline Neutral & 32 & $32.65 \%$ & 38 & $26.03 \%$ \\
\hline Total & 98 & $100 \%$ & 146 & $100 \%$ \\
\hline
\end{tabular}

From the above table, we see that the 50 collocations of happen with negative semantic prosody is the mainstream, accounting for $41.02 \%$ of the total. There are 32 collocations of happen with neutral semantic prosody, accounting for $32.65 \%$ of the total, while the 16 collocations of happen with positive semantic prosody accounts for $16.33 \%$ of the total. Typical examples include:

[12]
a. Letting everyone know exactly what did happen.
b. Or it could happen again.
c. Several things happened in very quick succession.
d. An accident happens to his passengers. 
f. I'll send you a message if anything important happens.

g. The famous festival in Spain was about to happen.

In Chinese, 87 collocations of fasheng with negative semantic prosody is the mainstream, accounting for $59.59 \%$ of the total. There are 38 collocations of fasheng with neutral semantic prosody, accounting for $26.03 \%$ of the total. The 21 collocations of fasheng with positive semantic prosody account for $14.38 \%$ of the total. Typical examples include:
a. 事故屡次发生。
shigu lüci fasheng
accident always happen
The accident always happen.
b. 空难发生了。
kongnan fasheng le
aircrash happened
The air crash happened.
c. 但谁也没有料到会发生越狱事件。
dan shui ye meiyou liaodao hui fasheng yueyu shijian
but who not expect would happen jailbreak event
But no one expect that jailbreak would happen.
d. 在这以前谁也没有对它发生过兴趣。

zai zhe yiqian shui ye meiyou dui ta fashengguo xingqu

at this before who not towards it happened interests

Nobody showed any interest in it before this.

f. 见面后不知发生了什么事情。

jianmian hou buzhi fasheng le shenm shiqing

meet after don't know happened what thing

Nobody knows what happened when they met each other.

Based on the raw data above, Chi-square tests were performed to find out whether the distribution of different semantic prosodies differs significantly. Table 13 shows the results of Chi-square tests of the comparison after running SPSS program. 
Table 13: Chi-square tests on semantic prosody of happen and fasheng

\begin{tabular}{|l|l|l|l|}
\hline & $\chi^{2}$ & $d f$ & $p$ \\
\hline Positive & .172 & 1 & .678 \\
\hline Negative & 1.749 & 1 & .186 \\
\hline Neutral & 1.258 & 1 & .262 \\
\hline
\end{tabular}

For Table 13, degree of freedom is 1, the calculated Chi-square value is $.172,1.749$ and 1.258 respectively, much smaller than the critical value 3.84 at five percent level. The calculated significance value is $.678, .186$, and .262 respectively, all greater than .05 . Thus we may conclude that there is no significant difference between the semantic prosody of happen and fasheng.

\subsubsection{Positive semantic prosody of happen and fasheng}

Of the 16 examples of collocations of happen with positive semantic prosody, 11 instances belong to syntactic pattern I "SOMETHING HAPPEN". The collocations of happen with positive semantic prosody are anything important, festival, good things, promotion and several pronouns such as it, this, that, what. We can easily distinguish the positive semantic prosody from those nominal collocations. As for those pronoun collocations, we can still tell from the specific contexts that happen in those contexts are associated with good things. Several examples are given as follows:

[14]
a. I'll, ah, send you a message if anything important happens.
b. The famous La Tomatino Festival in Spain was about to happen.
c. Some good things are happening along this line.
d. Unfortunately, this has not happened and we have seen continued erosion in the Banks lending margins.

The adjective important and good in example [14a] and [14c], the event noun festival in example [14b] indicate the positive semantic prosody of happen. In example [14d], double negations unfortunately and not also indicate that what would happen should be good thing.

Of the 21 examples of collocations of fasheng with positive semantic prosody, 18 instances belong to syntactic pattern I "EVENT-NOUN fasheng \& fasheng EVENT-NOUN". The positive collocations are: bianhua 变化 (change), biange 变革(transform), xiaoli 效力(effect), xingqu 兴趣(interest), fuwu de tigong 服务的提供(service provision), shijian 事件(event), wusi yundong 五四运动(May Fourth Movement), shenme 什么(what). Bianhua 变 化(change), and shenme 什么(what) may seem neutral, carrying no affective meaning. However, we can tell from the referents in the specific contexts that those collocations are associated with good changes. Some examples of the collocations with positive semantic prosody are given as follows:

[15]

a.更重要的是使原料发生“质”的变化, 最后构成菜肴的完美属性。

geng zhongyao de shi shi yuanliao fasheng zhidebianhua, zuihou goucheng caiyao de wanmei shuxing.

More important is make raw material happen qualitative change at last form 
dish perfect property

Most of all, the raw material should have qualitative changes so as to make the menu perfect.

b.公公婆婆对她的态度发生了历史性的变化，空前的呵护和体贴。

gonggongpopo, dui ta de taidu fasheng-le lishixing de bianhua, kongqian de hehu he titie.

Parents-in-law towards her attitude happened historical change unprecedented

caring and considerate

Historic changes have occurred in parents-in-law's attitudes towards her, they became unprecedented caring and considerate.

In example [15a], zhi de bianhua (qualitative changes) may be good or bad, but we can infer from goucheng caiyao de wanmei shuxing (make the menu perfect) that good things happened to the material. In example [15b], taidu de bianhua (the change of attitudes) may be good or bad, however, we can infer from kongqian de hehu he titie (unprecedented caring and considerate) that the parents-in-law's attitudes to her changed from bad to good.

The collocations of both happen and fasheng with positive semantic prosody constitutes a low proportion. Examples of the collocations of happen with positive semantic prosody occur 16 times, accounting for $16.33 \%$ of the total occurrences, and that of fasheng 21 times, accounting for $14.38 \%$ of the total occurrences. According to the Chi-square tests, there is no significant difference of the positive semantic prosody between happen and fasheng.

\subsubsection{Negative semantic prosody of happen and fasheng}

Collocations of happen and fasheng with negative semantic prosody constitutes a high proportion. Examples of collocations of happen with negative semantic prosody occur 50 times, accounting for $41.02 \%$ of the total. The 87 examples of collocations of fasheng with negative semantic prosody account for $59.59 \%$ of the total. Of the 50 collocations of happen with negative semantic prosody, only 7 are nominal collocations. The rest are pronouns, which refers to the above or following contexts. Of the 87 examples of collocations of fasheng with negative semantic prosody, 74 examples are nominal collocations. We can tell from this that in Chinese, the things that happened is specifically identified in most of the cases; While in English, we have to infer from the context what happened in most of the cases. According to the Chi-square tests, there is no significant difference of the negative semantic prosody between happen and fasheng.

The nominal collocations of happen with negative semantic prosody are: misfortune, bad weather, accident, horror, bad weather, the worst, and the tragedy. It is easy to tell that all those seven collocations contain a negative connotation.

[16]
a. The tragedy did not happen.
b. An accident happens to his passengers.
c. Bad weather happened on this first setting out.
d. A misfortune happened.

e. She and Winifred were sitting together on the bridge, he told her that things had happened while he was studying abroad that he was sorry for. 
f. He just felt bad about what had happened.

In the example [16a], [16b], [16c], and [16d], the event nouns tragedy, accident, bad weather, and misfortune clearly indicate that what happened or is happening is bad. In example [16e], we can infer from sorry for that the things that had happened are not good. In like manner we can infer from felt bad in example [16f] that what had happened is bad.

The nominal collocations of fasheng with negative semantic prosody cover a wide range of unpleasant things. A semantic preference of "calamities, diseases and hurts, criminals and bad events, and bad changes" can be drawn form the nominal collocations of fasheng with negative semantic prosody. Nominal collocations express semantic preference of "calamities" are: dahuo 大火(fire), huozai 火灾(fire), dizheng 地震(earthquake), fengbao 风 暴(storm), kongnan 空难(air crash), qihuo 起火(on fire), baozha 爆炸(explosion), kuangnan 矿难(mining accident), yiwai 意外(accident), zaihai 灾害(scourge). Nominal collocations express semantic preference of "diseases and hurts" are: binghai 病害(disease), ganran 感染(infection), jibing 疾病(disease), gongshang 工伤(accident at work), siwang 死亡(death). Nominal collocations express semantic preference of "criminals and bad events" are: anjian 案件(case), can'an 惨案(catastrophe), chongtu 冲突(conflict), dashi 大事(great invent), dongdan 动荡(turbulence), guzhang 故障(breakdown), haojie 浩劫(great calamity), huoshi 祸事(disaster), jiuge 纠葛(dispute), duoluo 酵落 (degeneration), qiangjie'an 抢劫案(case of robbery), zhengyi 争议(dispute), zuizaodeshi 最糟的（事) (the worst thing), zheyimu 这一幕(this occasion), saoluan 骚乱(riot), shigu 事故(accident), shijian 事件(event), shiqing 事情 (thing), sunhuai 损坏(damage), taotuo 逃脱(eacape), ganshe 干涉(intervene). Nominal collocations express semantic preference of "bad changes" are: bianhua 变化(change), bianxing 变形(distortion), bianyi 变异 (aberrance), houguo 后果(consequences), huhua 糊化(pasting), kunnan 困难(difficulty), toujixingpaomo 投机性泡 沫(speculative froth), tonghuopengzhang 通货膨胀(inflation), weiji 危机(crisis), wenti 问题(problem).

Some examples are given below:

a.地貌不稳定，以前曾发生过山坡垮塌伤人事故。

dimao bu wending, yiqian ceng fasheng guo shanpotanta shangren shigu.

Landform not stable once happened landfall hurt people accident

The landform structure is unstable, there were accidents caused by landfall.

b. 喜灵洲從教所 446 名囚犯在夜间发生骚乱。

Xilingzhou chengjiaosuo 446 ming qiufan zai yejian fasheng saoluan

Hei Lei Chau Inmate Centre 446 prisoners at night happen riot

Riot was held at night in Hei Lei Chau Inmate Centre by 446 prisoners.

c.空难发生后，心急如焚的乘客亲属先是赶往伊斯坦布尔。

kongnan fasheng hou, xinjirufen de chenke qinshu xianshi ganwang Istanbul air crash happen after demented passenger relatives first go to Istanbul

When the air crash happened, the demented relatives of the passengers went to Istanbul at once.

d.魏家坪发生了一场惨烈异常的矿难。

Weijiaping fasheng le yichang yichang canlie de kuangnan 
Weijiaping happened a unusual deadly mining accident

A most deadly mining accident happened in Weijiaping.

e.但最糟的不总是发生; 我们都有失败的时候。

dan zuizao de bu zongshi fasheng; women dou you shibai de shihou

but the worst not always happen we all have fail time

But the worst things do not always happen, we all had failed once.

In example [17a], shanpotanta (landfall), shigu (accident) make clear that what happened is bad. Saoluan (riot) in example [17b], kongnan (air crash) in example [17c], and zuizao de (the worst things) in example [17e] indicate that bad things happened. In example [17d], kuangnan (mining accident), yichang canlie (most deadly) indicate that what happened is extremely bad.

\subsubsection{Neutral semantic prosody of happen and fasheng}

According to the Chi-square tests, there is no significant difference between happen and fasheng with respect to the neutral semantic prosody: both constitute a relatively low proportion. We closely examined those examples and had them analyzed below.

Examples of collocations of happen with neutral semantic prosody occur 32 times, accounting for $32.65 \%$ of the total. Most of them are collocated with pronouns. In these examples, happen has a strong tendency to indicate the semantic preference of uncertainty and fortuity. What, the commonest collocation with happen, occurs 26 times. In these occasions, the answer is genuinely unknown and to be sought. If things happen by chance, it is a short step for this item to appear in environments where an event is uncertain, not yet known or impossible to be known, or where it is awaiting an explanation. It appears very frequently with all sorts of modals of possibility, expressing a lack of certainty or non-factuality. In example [18a] and [18b], the semi-modals might and would clearly imply the uncertainty of the things. It also appears in varieties of conditional or hypothetical constructions, again reflecting absence of factuality, as illustrated in example [18c]: if implies the absence of factuality. There are still more cases which express that an event is indeterminate or that its explanation is not known, such as in example [18d], and [18e].

[18]

a. You see, all kinds of things might happen.

b. Nobody knew what would happen to human beings in weightlessness.

c. What happens if you complain to the police of my having kidnapped and raped you?

d. She went down to look about her and to wonder what was going to happen next.

e. The public need to be given realistic expectations about what will happen after the process concludes.

There are 38 examples of collocations of fasheng with neutral semantic prosody, accounting for $26.03 \%$ of the total. Most of the nominal collocations are related to changes that may be good or bad. The uncertainty of the changes also indicates that fasheng with a neutral semantic prosody has a strong semantic preference of uncertainty. The collocations are: bianhua 变化(change), bianqian 变迁(variance), fanying 反应(response), gaibian 改变(transform)，guanxi 关系(relation), jiaocha 交叉(intersect), lianxi 联系(contact), qingkuang 情况 (situation), duihua 对话(dialogue), guanlian 关联(relationship), ganqing 感情(sentiment), gushi 故事(story), geju 格局(structure). The other nominal collocations are shenme 什么(what), shenmeshi 什么事(what thing), shi 事 
(thing), shijian 事件(event), shiqing 事情(thing), shishi 事实(fact), zheyangdeshi 这样的事(this thing), zheyimu 这 一幕(this sence), yiqie 一切(all the things), yundong 运动(movement). Several examples are:

[19]

\section{a.人类学的基本原则也没有发生根本的改变。} renleixue de jiben yuanze ye meiyou fasheng genben de gaibian anthropology basic principle not happen ultimate change There is no ultimate change in the basic principle of anthropology.

b.见面后不知发生了什么事情, 刘露再不理他。 jianmian hou buzhi fasheng le shenme shiqing, Liu Lu zai bu li ta meet after don't know happened what thing Liu Lu ever not respond him We don't know what happened when they met, Liu Lu does not speak to him anymore. c.我们不知道究竟哪一种情况会发生。 women buzhidao jiujing nayizhong qingkuang hui fasheng we don't know indeed which one situation would happen We don't know what will actually happen.

In example [19a], there is no clear indication of whether the changes that take place should be good or bad. In example [19b] and [19c], the predicate buzhi and buzhidao (don't know) indicate uncertainty and fortuity of the things that have happened or will happen.

From those data analysis we observe that both happen and fasheng co-occur more often with negative words than positive words. It can be inferred that both happen and fasheng are more towards the negative side on the positive-negative continuum since it is primed to occur with "bad things". In addition to its negative semantic prosody, happen and fasheng have a strong tendency to indicate uncertainty and fortuity, to appear in environments where things are not fully known or determined and to co-occur with items which express this general semantic area.

\section{Conclusions}

This paper has sought to examine the Natural Semantic Metalanguage Theory by conducting a contrastive study on English and Chinese semantic prime happen and fasheng. As it was developed and tested by using corpus data, the work presented here has been able to overcome the inaccuracies and biases inherent in the previous intuition-based research, thus provide a more accurate and comprehensive understanding of semantic primes in both English and Chinese. From both quantitative and qualitative analysis, this thesis holds the view that semantic prime happen is identical with its Chinese counterpart fasheng.

\subsection{Major Findings of the Research}

In order to test the NSM Theory, we conducted a corpus-based contrastive study on English and Chinese semantic prime happen and fasheng. By analyzing different meanings of happen and fasheng, we found that though there is a significant difference between the overall distribution of happen and fasheng, there is no significant difference between the distribution of the semantic meaning of happen and fasheng in the comparable corpus. Then, based on the concordance lines, we identified three syntactic patterns for happen 
and fasheng:

I. SOMETHING HAPPEN

EVENT-NOUN fasheng

fasheng EVENT-NOUN

II. SOMETHING HAPPEN TO X [Undergoer]

EVENT-NOUN fasheng zai X [Undergoer] (de) shenshang

X [Undergoer] fasheng EVENT-NOUN

III. SOMETHING HAPPEN IN PLACE/TIME

EVENT-NOUN fasheng zai NP TIME/PLACE

NPTIME/PLACE fasheng EVENT-NOUN

To investigate the usage in terms of different syntactic patterns, we calculated the frequency of each syntactic pattern, and found that there was no significant difference between the distribution of the three syntactic patterns of happen and fasheng. After that, we went on with the exploration of different colligation types within each syntactic pattern. We separated syntactic pattern I into two colligation types, namely: "n./ pron. + V. or V. + n." and "n./ pron. + V. + adv. or n./ pron. + adv. + V." In syntactic pattern II, we identified two colligation types "n. + V. + n." and "n./ pron. + prep. + V. or n./ pron. + V. + prep." In syntactic pattern III, we identified two colligation types "V. + locus" and "V. + Time".

Finally, we analyzed the semantic prosody, semantic preference and collocation of happen and fasheng, from which we observed that except for those collocations associated with uncertainty and fortuity, both happen and fasheng co-occur more often with negative words than positive words. It can be inferred that both happen and fasheng are more towards the negative side on the positive-negative continuum since it is primed to occur with "bad things" and that there is no significant difference of the semantic prosody of happen and fasheng.

\subsection{Limitations}

It should be admitted that although strenuous efforts have been made, the present study is far from perfect. This study is exploratory in nature, and some difficult issues have not yet been tackled adequately.

First, due to the focus and the space of the thesis, we had to restrict the investigation to a single semantic prime happen in English and its Chinese counterpart fasheng. The selected word is the subject choice of the author and it is just a tip of the iceberg of the total more than 60 semantic primes.

Second, the size of the comparable corpus is relatively small in light of contrastive study. Therefore, the results of the current study may be modified by other larger corpora's evidence.

\subsection{Suggestions for Further Research}

It is clear that much work remains to be done to shed further light on the corpus-based Natural Semantic Metalanguage Theory study. First, it is suggested that further studies should be carried out among larger corpora. If the size of the corpus is expanded, the reliability of the research results will be increased. Secondly, more extensive investigations should be carried out by examining all the other semantic primes.

All in all, the Natural Semantic Metalanguage Theory offers a new and promising perspective for semantics and, especially, lexical semantics. More inter-lingual and cross-lingual researches could be done concerning the 60 
or more semantic primes. The application of the principles also deserves exploration.

\section{Conflict of interest}

None to declare.

\section{Author biography}

Yajun Wang, PhD candidate at School of Interpreting and Translation Studies, Guangdong University of Foreign Studies, Guangzhou, China. E-mail address: 20183648@qq.com

\section{References}

1. Aijmer, J., \& Altenberg, B. (eds.). 1991. English corpus linguistics: studies in honor of Jan Svartvik. London: Longman.

2. Arnauld, A., \& Nicole, P. 1996. Logic or the Art of Thinking. Translated by Jill Vance Buroker. Cambridge: Cambridge University Press.

3. Biber, D. et al. 2000. Corpus linguistics. Beijing: Foreign Language Teaching and Research Press.

4. Bulter, C. 1985. Statistics in linguistics. New York: Basil Blackwell.

5. Chappell, H. 2002. The Universal Syntax of Semantic in Mandarin Chinese. In: Goddard, C., \& Wierzbicka, A. (eds.). Meaning and Universal Grammar: Theory and Empirical Findings. Amsterdam: John Benjamins.

6. Collins CoBuild Advanced Learner's English Dictionary. 2006. Beijing: Foreign Language Teaching and Research Press.

7. Firth, J. R. 1957. A synopsis of linguistic theory, 1930-1955. In Palmer, F. R. (ed.),

8. Selected papers of J. R. Firth 1952-1959. London: Longman.

9. Fillmore, C. 1992. Computer-aided armchair linguistics. In McEnery, A., \& Wilson, A. 1996. Corpus Linguistics. Edinburgh: Edinburgh University Press.

10. Gao, Y. 2003. Perspectives on Politeness in English and Chinese Cultures. Chongqing: Southwestern Normal University.

11. Goddard, C. 1997. Cultural values and 'cultural scripts' in Malay (Bahasa Melayu). Journal of Pragmatics 27: 183-201.

12. Goddard, C. 1998a. Bad arguments against semantic primitives. Theoretical Linguistics Vol. 24: 129-156

13. Goddard, C. 1998b. Semantic analysis: a practical introduction. Oxford: Oxford University Press.

14. Goddard, C. 2001. Lexico-semantic universals: a critical overview. Linguistic Typology 5(1): 1-66.

15. Goddard C. 2002. Ethnosyntax, ethnopragmatics, signfunctions, and culture. In Enfield. N. J. (ed.), Ethnosyntax: explorations in grammar and culture. Oxford: Oxford University Press.

16. Goddard, C. 2003. Whorf meets Wierzbicka: variation and universals in language and thinking. Language Sciences 25(4): 393-432.

17. Goddard, C. 2006. Natural Semantic Metalanguage. In Keith Brown. Encyclopedia of Language and Linguistics, 2nd edition. Oxford: Elsevier. 
18. Goddard, C., \& Wierzbicka, A. (eds.). 1994. Semantic and lexical universals-theory and empirical findings (Vols I and II). Amsterdam: John Benjamins.

19. Goddard, C., \& Wierzbicka, A. (eds.). 2002. Meaning and universal grammar-theory and empirical findings. Amsterdam: John Benjamins.

20. Gries, S. T. 2003. Multifactorial analysis in corpus linguistics: a study of particle placement. New York: Continuum.

21. Gui, S. C. 2003. Zhong Guo Xue Xi Zhe Ying Yu Yu Liao Ku. (Chinese Learner English Corpus). Shanghai: Shanghai Foreign Language Education Press.

22. He, A. P. 2004. Yu Liao Ku Yu Yan Xue Yu Ying Yu Jiao Xue. Beijing: Foreign Language Teaching and Research Press.

23. He, A. P. (ed.). 2004. Application of Corpora to Foreign Language Education: Theory and Practice. Guangdong: Guangdong Higher Education Press.

24. Hoey, M. 2000. A world beyond collocation: new perspectives in vocabulary teaching. In M. Lewis (ed.), Teaching Collocation: Further Developments in the Lexical Approach. London: Language Teaching Publications.

25. Hu, X. Y. 2006. A Corpus-based Study on the Translational Norms of Contemporary Chinese Translated Fiction. Shanghai: East China Normal University.

26. Huang, C. N., \& Li, J. Z. 2002. Yu Liao Ku Yu Yan Xue. Beijing: The Commercial Press.

27. Hunston, S. 2002. Corpora in applied linguistics. Cambridge:Cambridge University Press.

28. Jackendoff, R. 1983. Semantics and cognition. Cambridge, MA: MIT Press.

29. Jackendoff, R. 1990. Semantic Structures. Cambridge, MA: MIT Press.

30. Kennedy, G. 2000. An Introduction to Corpus Linguistics. Beijing: Foreign Language Teaching and Research Press.

31. Kjellmer, G. 1994. A dictionary of English collocations : based on the Brown corpus : in three volumes. Oxford: Oxford University Press.

32. Leibniz, W. 1973. Leibniz: Philosophical Writings, (ed.) G. H. R. Parkinson. London: Dent.

33. Lu, Z. 2003. On Semantic Prime and Cultural Script. Journal of Foreign Languages 5: 27-34

34. Lu, Z., \& Zhu, H. Q. 2004. Natural Semantic Metalanguage Theory on Cognition and Language. Academic Research 8: 143-147

35. Lu, Z. 2005. The Methodology of Cognitive Linguistics. Journal of Sichuan International StudiesUniversity 5: 84-88

36. Lyons, J. 1977. Semantics. Cambridge: Cambridge University Press.

37. Lyons, J. 1995. Linguistic Semantic: An Introduction. Cambridge: Cambridge University Press.

38. Ma. Y. 2001. Semantic Attainment in Interlanguage: A Corpus-Based Study of Verb Uses Through Chinese L2 Learners' Written English Texts. Beijing: China Science and Culture Press.

39. McEnery, T., \& Wilson, A. 1996. Corpus Linguistics. Edinburgh: Edinburgh University Press. 
40. McEnery, T. et al. 2006. A glossary of corpus linguistics Edinburgh: Edinburgh University Press.

41. Meyer. C. F. 2002. English Corpus Linguistics: An Introduction. Cambridge: Cambridge University Press.

42. Nation, P., \& Waring, R. 2002. Vocabulary Size, Text Coverage and Word Lists. Vocabulary: Description, Acquisition and Pedagogy. Shanghai: Shanghai Foreign Language Education Press.

43. Oxford Advanced Learner's English-Chinese Dictionary. 2004. Oxford: Oxford University Press.

44. Partington, A. 1998. Patterns and meanings: using corpora for English research and teaching. Amsterdam: John Benjamins.

45. Partington, A. 2004. "Utterly content in each other's company": Semantic prosody and semantic preference. International Journal of Corpus Linguistics 9(1): 131-156

46. Pu, J. Z. 2004. Learner behavior of verbs: Colligation, collocation and chunk. Ka91. Corpus, Concordance, Collocation. Oxford: Oxford University Press.

47. Stubbs, M. 1995. Corpus Evidence for Norms of Lexical Collocation. In Cook, G., \& Seidlhofer, B. (eds.), Principle \& Practice in Applied Linguistics. Studies in Honour of H.G. Widdowson. Oxford: Oxford University Press.

48. Stubbs, M. 1996. Text and corpus analysis. Oxford: Blackwell.

49. Stubbs, M. 2001. Words and Phrases. Oxford: Blackwell.

50. Susan. 2002. Corpora in Applied Linguistics. Cambridge: Cambridge University Press.

51. Wang, P. R. 2002. An Advanced course of English Lexicography. Shanghai: Shanghai

52. Foreign Language Education Press.

53. Wang, J. X. 2005. Ji Suan Ji Yu Liao Ku de Jian She Yu Ying Yong. Beijing: Tsinghua University.

54. Wang, K. F. 2004. Shuang Yu Dui Ying Yu Liao Ku Yan Zhi Yu Ying Yong. Beijing: Foreign Language Teaching and Research Press.

55. Wei, N. X. 1999. Towards defining collocations: a practical scheme for study of

56. collocations in EAP texts. Unpublished Ph.D. dissertation. Shanghai: Shanghai Jiaotong University.

57. Wei, N. X. 2003. Fifty years of collocational study: Conceptual changes and methodological developments. Journal of PLA University of Foreign Languages 2: 11-15.

58. Wei, N. X. et al. 2005. Corpora in use. Shanghai: Shanghai Foreign Language Education Press.

59. Wierzbicka, A. 1972. Semantic primitives. Frankfurt: Athenaum.

60. Wierzbicka, A. 1985. Lexicography and conceptual analysis. Ann Arbor: Karoma.

61. Wierzbicka, A. 1987. English speech act verbs: a semantic dictionary. Sydney/New York: Academic Press.

62. Wierzbicka, A. 1991. Cross-Cultural Pragmatics: The Semantics of Human Interaction. Berlin: Mouton de Gruyter.

63. Wierzbicka, A. 1992. Semantics, Culture and Cognition. Oxford: Oxford University Press.

64. Wierzbicka, A. 1996a. Semantics: Primes and Universals. Oxford: Oxford University Press. 
65. Wierzbicka, A. 1996b. Japanese cultural scripts: cultural psychology and 'cultural grammar'. Ethos 24: 527-555.

66. Wierzbicka, A. 1997. Understanding cultures through their key words. Oxford: Oxford University Press.

67. Wierzbicka, A. 1998. German 'cultural scripts': public signs as a key to social attitudes and cultural values. Discourse \& Society 9: 241-282.

68. Wierzbicka, A. 1999a. What did Jesus mean? The Lord's Prayer translated into universal human concepts. In: Bisschops, R., \& Francis, J. (eds.), Metaphor, Canon and Community. Berlin: Peter Lang.

69. Wierzbicka, A. 1999b. Emotions across languages and cultures. Cambridge: Cambridge University Press.

70. Wierzbicka, A. 2002. Australian cultural scripts-'bloody' revisited. Journal of Pragmatics 34: 1167-1209.ifeng: Hernan University Press.

71. Saeed, J. 1997. Semantics. Oxford: Blackwell Publishers Inc.

72. Scott, M. 1999. WordSmith Tools 5.0. Oxford: Oxford University Press.

73. Sinclair, J. (ed.). 1991. Corpus, Concordance, Collocation. Oxford, UK: Oxford University Press.

74. Wittgenstein, L. 1953. Philosophical Investigations. Trans. G.E.M. Anscomb. Oxford: Blackwell.

75. Xian Dai Han Yu Ci Dian. 2005. Beijing: The Commercial Press.

76. Xian Dai Han Yu Ci Hai. 1994. Beijing: People's China Press.

77. Yang, H. Z. 2002. An Introduction to Corpus Linguistics. Shanghai: Shanghai Foreign Language Education Press.

78. Yang, H. Z. et al. (eds.). 2005. Corpus-based analysis of Chinese Learner English. Shanghai: Shanghai Foreign Language Education Press. 